\title{
Effect of forward head and rounded shoulder posture on hand grip strength in asymptomatic young adults: a cross- sectional study
}

Dalia Mohammed Mosaad ${ }^{1,2}$, Amr Almaz Abdel-aziem ${ }^{3^{*}}$ (D), Ghada Ismail Mohamed', Enas Anwr Abd-Elaty ${ }^{4}$ and Karima Salah Mohammed ${ }^{1}$

\begin{abstract}
Background: Forward head and rounded shoulder posture (FHRSP) is a common clinical postural misalignment. It leads to flexion posture of the spine which increases the amount of tension on the nerve roots, which inversely affects muscle strength and function of the upper extremity. So, this study was conducted to examine the effect of FHRSP on hand grip strength in asymptomatic young adults and to explore the relationship between the craniovertebral angle (CVA) and hand grip strength.

Results: There was no significant difference in hand grip strength between the groups $(p=0.812)$. There was no correlation between the CVA and right and left hand grip of the normal group ( $p=0.840,0.816$ respectively), rounded shoulder posture (RSP) group ( $p=0.523,0.650$ respectively), and FHRSP group ( $p=0.855,0.736$ respectively). Regarding the right and left hand grip strength, there was no significant difference between the groups ( $p=0.798,0.826$ respectively). The right hand grip strength was significantly higher than the left hand for all groups $(p=0.001)$.

Conclusion: This study displayed that hand grip strength was not affected by FHRSP nor RSP in asymptomatic young adults. Moreover, the degree of the CVA was not associated with an inverse effect on hand grip strength.
\end{abstract}

Keywords: Craniovertebral angle, Forward head posture, Hand grip strength, Rounded shoulder posture

\section{Background}

Using personal computers and smartphones leads to sustained and frequent periods of sitting behind monitors and visual display terminal syndrome. Cumulative trauma disorder caused by maintaining the same posture for long periods of time is the expected outcome for these risk factors [1]. One of the common clinical postural misalignments is the forward head and rounded shoulder posture (FHRSP) [2]. The prevalence of forward head posture (FHP) and rounded shoulder posture (RSP) in a group of 20-50-year-old healthy subjects was

\footnotetext{
*Correspondence: amralmaz@yahoo.com; amralmaz74@gmail.com ${ }^{3}$ Department of Biomechanics, Faculty of Physical Therapy, Cairo University, 7 Ahmed Elziat Street, Ben Elsaryat, Eldokki, Giza 12611, Egypt

Full list of author information is available at the end of the article
}

reported as $66 \%$ had a FHP, $73 \%$ had a right RSP, and $66 \%$ had a left RSP [3].

The prevalence of common faulty postures among adolescents showed that the most common faulty posture was uneven shoulder level (36\%), followed by forward head posture (FHP) (25\%) [4]. The FHP is prevalent also among university students, and it is associated with shoulder rolling [5]. More than $80 \%$ of patients with myofascial pain syndrome have FHP and rounded shoulder posture (RSP) [6].

There was an increased extension of the atlantooccipital joint and the upper cervical vertebrae associated with flexion of the lower cervical and upper thoracic vertebrae in subjects with FHP [7]. Biomechanically, during flexion of the spine, there is an increase in the amount of tension on the nerve roots, which affects 
muscle strength [8]. Flexion of any part of the spine may put axial tension on the nerve roots [9]. RSP is characterized by a protruded acromion process of the shoulder joint in relation to the line of gravity; it causes stooped posture with elevation, protraction, and downward rotation of the scapula. Moreover, the angle between the lower neck bone and the upper spine increases [10]. It shortens and changes the function of the pectoralis minor muscle. Moreover, it had an increased incidence of inter-scapular and cervical pain [11].

The cervical dysfunctions that appear in the youth stage are only a result of exposure to the use of smartphones for a long time in childhood. So, the American Academy of Pediatrics in 2014 recommended parents to limit children between 6 and 18 years to use digital media no more than $2 \mathrm{~h}$ a day [12]. Therefore, age was considered as the main cause of the changeability in stiffness, elasticity, and alteration of the mechanical parameters of the cervical region [13]. Therefore, people who do not presently experience clear musculoskeletal symptoms may show symptoms later if they extendedly used smartphones.

Sleeping with the head elevated too high and extended use of computers and smartphones are the factors responsible for FHRSP development [14]. FHRSP is associated with changes in the scapular positions, kinematics, and muscle activities that consequently increase muscle tension and strain around the neck and shoulders, causing various neuromuscular symptoms that affect the upper body [15]. Normally, during hand functions, proximal stability is provided by the pre-scapular muscles [16]. In FHRSP, the proximal stability around the shoulder complex is negatively affected by disturbance of the scapulohumeral rhythm which may negatively affect the rotator cuff muscles which provide the dynamic proximal stability of the shoulder joint $[17,18]$.

Hand grip strength results from the combined contraction of extrinsic and intrinsic hand muscles; this leads to flexion of the hand joints [18]. The body and upper limb positions can affect its strength $[19,20]$. The grip strength measurement has been a non-invasive marker of muscle strength of the upper extremities [21] and is a widely accepted indicator of functional integrity of the upper extremity [8]. So, the appropriate scapular position improves the upper limb function [16].

There is a correlation between the FHP severity, craniovertebral angle (CVA), and neck disability indicators. It was reported that the degree of FHP depends on the CVA, which can be used as a significant indicator of neck functional disability [10, 22]. Moreover, there was a moderate to good negative correlation between CVA and neck pain in young adults [23].

However, most of the earlier researches have been limited to the evaluation of the functional level and muscular strength and activity in subjects with FHP, discovering how much the movement and pain influence patients with FHP [24-27] or is it feasible to use the CVA to predict the incidence of pain [28]. To date, there was no study examining the effect of FHP and RSP on hand grip strength. So, this study was conducted to examine the consequence of FHRSP on hand grip strength in asymptomatic young adults and to explore the relationship between the CVA and hand grip strength.

\section{Methods}

This study was designed as an observational crosssectional study. The study was carried out in agreement with the values of the Helsinki Declaration and was approved by the ethical committee of the Faculty of Physical Therapy, Cairo University (P.T.REC/012/001881). It was conducted between May and July 2018.

A random sample of three hundred and thirty-five participants was recruited using publically distributed posters and online social media and by verbal invitation from the undergraduate students of Faculty of Physical Therapy, Cairo University. They were screened for their eligibility to participate in the study. Only one hundred two right-handed participants of both genders were found meeting the inclusion criteria [age ranged from 19 to 24 years and have normal body mass index (BMI < 25)] and enrolled in this study (Fig. 1) after signing an informed consent. They were excluded if they had cervical radiculopathy; previous surgery in the upper limb, hand, and neck; carpal tunnel syndrome; rheumatoid arthritis; and hand deformities and if they were athletes.

While CVA is considered as a valid and reliable assessment method to assess FHP [29], the participants were assigned into three groups according to deformity type; group A consisted of 30 participants with normal posture (CVA $>50$ and distance from the posterior acromion to the table $<2.5 \mathrm{~cm}$ ), group B consisted of 34 participants with RSP (CVA > 50 and distance from the posterior acromion to the table $>2.5 \mathrm{~cm}$ ), and group $\mathrm{C}$ consisted of 38 participants with FHRSP (CVA $<50$ and distance from the posterior acromion to the table $>2.5 \mathrm{~cm}$ ).

\section{Procedure}

\section{Measurements of the craniovertebral angle}

For the measurement of the FHP, the CVA was measured using the photogrammetric method. The intrarater and inter-rater evaluations of photogrammetry findings of the cervical spine standing sagittal posture were found to be reliable [30, 31]. The CVA lies between a horizontal line through the spinous process of the 7th cervical vertebrae and a line that passes through the tragus of the ear. It was assessed while the subject assuming a standing position, and a lateral view picture was taken from the dominant side by a digital camera [30] [Panasonic, Lumix, DMC-FZ5, Panasonic Inc., Japan, 


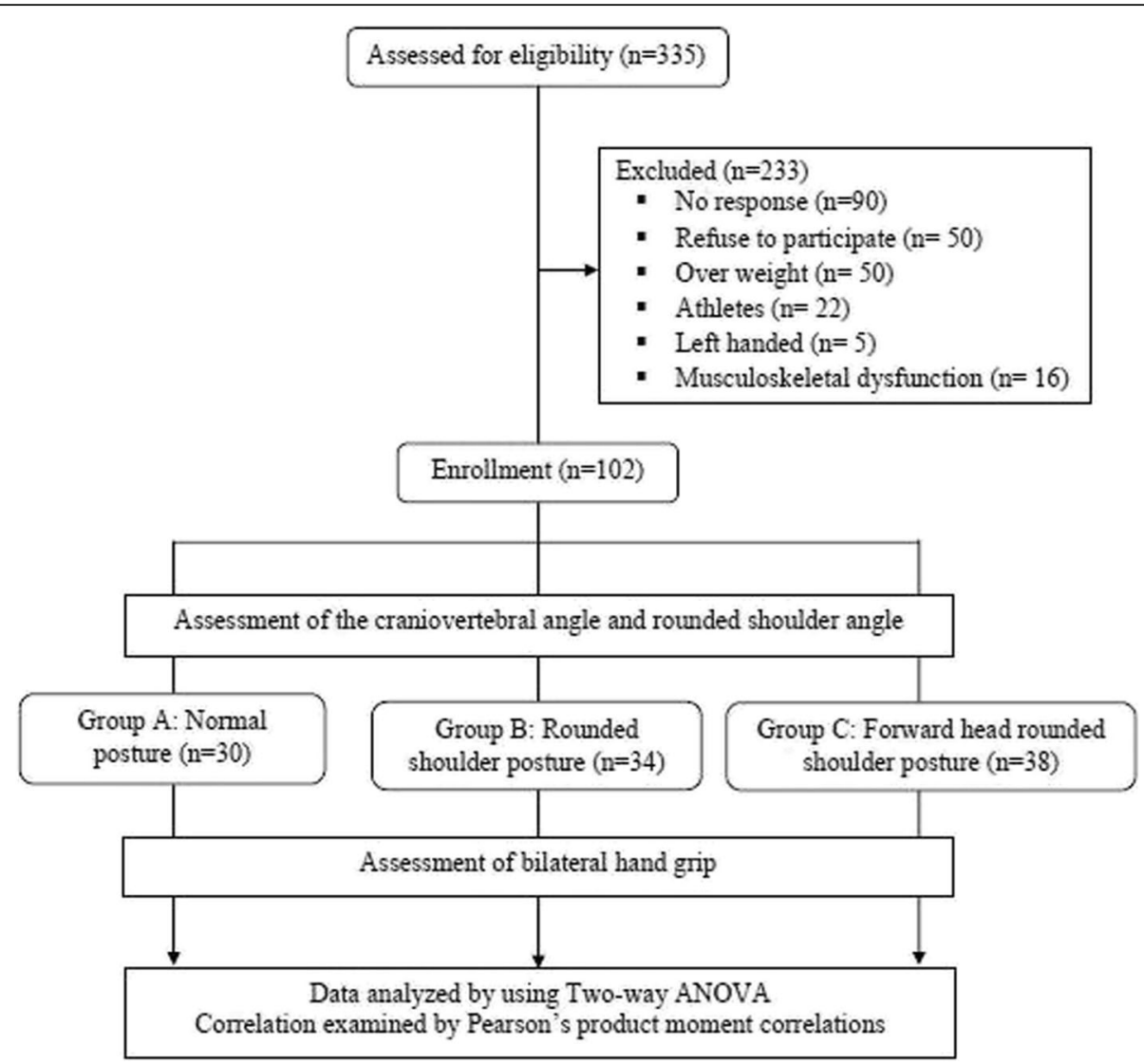

Fig. 1 The participants' flow chart

with a $35-\mathrm{mm}$ lens and $\times 12$ optical zoom and a built-in flash] that was placed on a tripod $1.5 \mathrm{~m}$ away from the subject and its base was adjusted at the subject's shoulder level. Three measurements were taken; then, the numbers were averaged [10]. The photos were analyzed by using the Surgimap software [32].

\section{Measurement of the rounded shoulder posture}

RSP was measured using the supine method. Participants were asked to lie in a supine position on a standard treatment plinth and assumed their natural relaxed posture with their arms on both sides and the elbows were flexed and rested against the lateral side of the abdomen. Then, the examiner measured the linear distance from the posterior aspect of the acromion process to the table by using a rigid plastic transparent right angle triangle. If the distance was $\geq 2.5 \mathrm{~cm}$, it means the participants have RSP [33]. Three measurements were registered; then, the average value was recorded [10].

\section{Hand grip strength assessment}

Hand grip strength of both hands was measured using the Jamar handheld dynamometer (serial number 1-800323-5547; SAMMONS PRESTON Company, Leicester,
England). Participants were seated on a standard height chair without armrests with the shoulder adducted and neutrally rotated, elbow flexed $90^{\circ}$, forearm in a neutral position, and the wrist in 0 and $30^{\circ}$ extension and 0 and $15^{\circ}$ ulnar deviation, which was measured by using a universal goniometer. The participants were asked to squeeze their hands on the dynamometer handle according to the following verbal orders (i.e., "one, two, three, squeeze... harder... harder..."). They were randomly assigned during testing the right or left hand by using a coin tossing. Three measurements of hand grip strength were registered for each hand; then, the average value was recorded [34], with a 1-min rest between the measurements to avoid fatigue [35].

\section{Sample size and data analysis}

Statistical Package for Social Sciences (SPSS) for Windows, version 23 (SPSS, Inc., Chicago, IL), was used to analyze the outcome measures. The sample size estimation was determined by using the statistical power analysis, which was based on the data from a pilot study conducted on 7 subjects, comparing the hand grip strength of both hands between three study groups. The effect size (ES) was 0.3 , which was considered a medium 
effect by using Cohen's criteria [36], with power $=0.80$ and an alpha $=0.05$. The planned sample size required with this ES (G Power 3.1 or other software) was approximately 66 participants for the simplest between/withingroup comparison. Thus, our suggested sample size of 102 participants was more than enough to conduct the current study.

Preliminary assumption checking revealed that data was normally distributed with no outliers and did not violate the parametric assumption for the tested variables. The current study involved the handgrip strength as a dependent variable that was measured at two independent variables (tested group), between-subject factor which had three levels (group A represents the normal posture group, group B represents the RSP group, and group C represents the FHRSP group), and the side, within-subject factor which had two levels (right and left sides). Accordingly, a two-way analysis of variance (ANOVA) was used to evaluate the hand grip strength of both body sides of the three tested groups. Then, Pearson's product-moment correlation was used to explore the relationships between CVA and hand grip strength. The source of differences was determined by using the least significant difference test with the significance level was set at 0.05 for all tests.

\section{Results}

As indicated by the one-way ANOVA, there were no significant differences $(p>0.05)$ in the mean values of age, body mass, and height among the three tested groups. Chi-square revealed there were no significant differences among the three groups in sex distribution $(p>0.05)$ (Table 1).

There were no significant effects of the tested group on the hand grip strength $(F=0.209, p=0.812$, partial $\left.\eta^{2}=0.004\right)$. In addition, there were significant effects of side (the second independent variable) on the hand grip strength $\left(F=64.488, p=0.0001^{*}\right.$, partial $\left.\eta^{2}=0.394\right)$ within the groups. Also, the interaction between the two independent variables was not significant, which indicates that the effect of the tested group (first independent variable) on the hand grip strength was not influenced by the side (second independent variable) $(F=0.206, p=$ 0.814, partial $\eta^{2}=0.004$ ) (Table 2).

Multiple pairwise comparison tests were conducted by using the Tamhane post hoc test; the sample groups were not of equal number which revealed that there was no significant difference in the mean values at the left nor right side between each pair of the three groups (Table 3 ).

There was no correlation between the CVA and the right and left hand grip strength of the normal group $(p=0.840,0.816$ respectively), RSP group ( $p=0.523$, 0.650 respectively), and FHRSP group $(p=0.855$, 0.736 respectively) as shown in Table 4 .

\section{Discussion}

There was no research report about the effect of FHRSP on hand grip strength and the relationship between FHP and grip strength in a group of asymptomatic young adults. The results showed that there was no significant difference in hand grip strength among the three groups that may be attributed to several factors. Firstly, the participants were young asymptomatic, and the postural deformity was not severe enough to induce distal changes; this cause may also explain the lack of correlation between the FHP and grip strength. Secondly, they have not been exposed to long working hours yet. Thirdly, the participants' age is still young until the negative effects of RSP and FHRSP are shown.

It is noticed that the FHRSP did not affect the hand grip strength, and there was no correlation between the value of CVA, which represents the FHP, and grip strength that was supported by Zafar and Alghadir [37] who measured the hand grip strength by using a handheld dynamometer with nearly the same age group and concluded that there was no effect of head and neck positions on hand grip strength in healthy young adults. Furthermore, their findings agreed with Wong et al. [38] who found that there was no effect of head and neck positions on the strength of the elbow and hand muscle.

Table 1 Descriptive characteristics for all dependent variables for each group

\begin{tabular}{|c|c|c|c|c|}
\hline Outcomes & Normal group, $n=30$ & RSP group, $n=34$ & FHRSP group, $n=38$ & $p$ value \\
\hline Age, years & $21.33 \pm 1.17$ & $20.56 \pm 1.44$ & $20.79 \pm 1.38$ & 0.208 \\
\hline Height, cm & $165.57 \pm 8.27$ & $167.18 \pm 11.14$ & $168.53 \pm 8.54$ & 0.440 \\
\hline Weight, kg & $59.20 \pm 7.70$ & $62.12 \pm 9.86$ & $64.00 \pm 8.10$ & 0.079 \\
\hline $\mathrm{BMl}, \mathrm{kg} / \mathrm{m}^{2}$ & $21.53 \pm 1.65$ & $22.10 \pm 1.57$ & $22.45 \pm 1.63$ & 0.071 \\
\hline Sex, male/female & $16 / 14$ & $17 / 17$ & $18 / 20$ & 0.891 \\
\hline CVA, degrees & $55.20 \pm 2.78$ & $54.09 \pm 2.58$ & $47.03 \pm 2.42$ & $0.001^{*}$ \\
\hline Rounded shoulder angle, degrees & $2.40 \pm 0.30$ & $4.17 \pm 0.82$ & $4.18 \pm 0.89$ & $0.001^{*}$ \\
\hline
\end{tabular}

Data are presented as mean \pm standard deviation

$B M I$ body mass index, RSP rounded shoulder posture, FHRSP forward head and rounded shoulder posture

*Significant at $p<0.05$ 
Table 2 The effect of hand side on hand grip strength $(\mathrm{kg})$

\begin{tabular}{lllll}
\hline Outcomes & Normal group, $n=30$ & RSP group, $n=34$ & FHRSP group, $n=38$ & $p$ value \\
\hline Right hand & $30.13 \pm 9.79$ & $30.99 \pm 10.67$ & $29.43 \pm 9.06$ & 0.798 \\
Left hand & $27.55 \pm 9.83$ & $28.67 \pm 10.14$ & $27.31 \pm 9.41$ & 0.826 \\
$p$ value & 0.001 & 0.001 & 0.001 & \\
\hline
\end{tabular}

Data are presented as mean \pm standard deviation

$R S P$ rounded shoulder posture, FHRSP forward head and rounded shoulder posture

*Significant at $p<0.05$

The current results were supported by the findings of Sawyer [39] who did not found a significant difference in the strength of serratus anterior, posterior deltoid, infraspinatus, teres minor, and lower trapezius muscles between the FHRSP group and the normal posture group. This indicates that the proximal shoulder muscle strength was not affected by FHRSP and indirectly does not affect the distal hand muscles reflected by hand grip strength. Furthermore, these results could be explained by Talati et al. [40] who concluded that there is no significant association between FHP, thoracic kyphosis, and lumbar lordosis in normal adults aged 18-35 years, which supports the absence of correlation between the CVA and hand grip strength weakness.

The thoracic hyperkyphosis results in the protraction of the scapulae [16] that can negatively affect the lengthtension relationship of the rotator cuff and threaten the proximal stability of the arm [17] which decreases the upper limb function, and may indirectly affect grip strength. These results come against the finding of the present study that may be caused by applying the study on young adults who did not suffer from long working hours and who are not yet suffering from pain or any degenerative changes.

The present results are explained not only mechanically but also physiologically by the findings of Samaan et al. [41] who assess the effect of prolonged smartphone use on the cervical spine, hand grip strength, and median and ulnar nerve conduction velocities of the forearm in adolescent (14 to 18 years). Although they showed significant differences only in the conduction velocity of the ulnar nerve, there was no significant difference in hand grip strength between adolescent children who use smartphones less than $4 \mathrm{~h} /$ day and others who use smartphones more than $4 \mathrm{~h} /$ day. Moreover, prolonged use of smartphones increased the FHP and neck pain.

The hand grip strength was not influenced in asymptomatic young adults with RSP, which agreed with DiVetal et al. [42] who examined relaxed standing scapular positioning in healthy individuals. They found that there was no relationship between scapular positioning (scapular abduction) and strength of middle trapezius and pectoralis minor muscle strength. This means that the position of the scapula does not affect the strength of the muscles around the scapulae which are considered as proximal stabilizers of the shoulder (where their action is very important during hand gripping) so the hand grip will not be affected, which is supported by the finding of Kim and Kim [10] who concluded that the increased FHP did not develop RSP.

In addition, this result concurs with Smith et al. [43] who found that scapular protraction or retraction resulted in a significant reduction in isometric shoulder elevation strength. There is a reduction in shoulder elevation strength in either position of scapulae, which means that scapular position does not affect shoulder elevation strength and finally no effect on the hand grip strength. Moreover, these findings are coincident with the lack of association between CVA and hand grip strength of the current study.

It is noticed that the dominant hand grip strength was higher than the non-dominant hand in all groups, which could be explained by the findings of Incel et al. [44] who stated that the dominant hand grip strength was stronger than the left hand in right-handed subjects. They explained that by using the dominant hand in handling objects and activities of daily living. Moreover, Han et al. [45] reported that the right hand grip strength was 5-6\% higher than the left hand grip strength in right-handed subjects.

Amin et al. [8] found that changing the neck position affected the hand grip strength in males and females with the highest grip strength obtained at the neutral position of the neck which is inconsistent with the current findings. This controversy may be due to the complete range of neck flexion assumed intentionally by the subjects in their study, while in our study, the subject had FHRSP with upper cervical spine extension and lower cervical spine flexion that may cause the tension on the nerve roots, muscles, and soft tissues.

Table 3 Multiple pairwise comparison tests (post hoc tests) for the hand grip strength among different groups at both sides

\begin{tabular}{|c|c|c|c|c|}
\hline & & Group A vs. group B & Group A vs. group C & Group B vs. group C \\
\hline Right side & $p$ value & 0.99 & 0.98 & 0.98 \\
\hline Left side & & 0.98 & 0.99 & 0.99 \\
\hline
\end{tabular}

*Significant at $p<0.05$ 
Table 4 Correlation between the CVA (degrees) and hand grip strength (kg)

\begin{tabular}{lllll}
\hline & & Normal group, $r(p)$ & RSP group, $r(p)$ & FHRSP group, $r(p)$ \\
\hline CVA & Right hand & $0.039(0.840)$ & $-0.114(0.523)$ & $0.031(0.855)$ \\
& Left hand & $0.044(0.816)$ & $-0.081(0.650)$ & $0.056(0.736)$ \\
\hline
\end{tabular}

$r$ Pearson's correlation coefficient, RSP rounded shoulder posture, FHRSP forward head and rounded shoulder posture

*Significant at $p<0.05$

Moreover, the results of this study were in contrast with Ebram [46] who reported that the most discomfort, the greatest activity of the neck muscles (sternocleidomastoid-upper trapezius-erector spinae), and the least hand grip strength were found in the non-neutral and loaded position of the head and neck. This may be attributed to that the measurement position was totally different from the present study, and their subjects assumed full neck flexion with head loading. Furthermore, the current results disagreed with Yang et al. [47] who concluded that adjustment of the ideal position of the scapula improved the activity of the muscles surrounding the shoulder joint and increased hand grip strength. This contradiction may be caused by using small sample size, difference in measurement procedure, and conduction of their study on female subjects only.

The lack of correlation between the CVA and hand grip strength was consistent with the recent findings of Mosa [48] who concluded that there was no significant association between the severity of FHP, as measured by the craniovertebral angle, and upper limb anthropometry including the total upper limb, upper arm, forearm, and hand length in addition to mid-arm circumference in forty-one asymptomatic subjects with FHP. Moreover, there was no association between the CVA in female students with FHP and the value of the neck disability index [49]. However, there was a significant negative correlation between the CVA and flexion and extension position sense error in subjects with FHP [50]. The participants of the current study were asymptomatic patients which may be the cause of this controversy, and the degree of CVA was not enough to produce distal affections. Mateen et al. [51] cannot find a cause and effect relationship between CVA and pain of the cervical spine, and functional status of patients with carpal tunnel syndrome.

There are some limitations of the current study; there were few studies concerning the scope of the current study to compare the present results with them. So, further research is needed to study the effect of FHP and RSP on grip strength in symptomatic patients. Also, more studies should be conducted on older subjects as there is an inverse relationship between age and CVA [13]. Finally, the hand strength was only assessed by the hand grip strength without consideration of the thumb strength. Moreover, there was no measurement of the upper extremity physical functions or strength of more proximal joints in asymptomatic young adults with FHP and RSP, which may provide clinicians and researchers therapeutic tools to reduce the possibility of further upper extremity musculoskeletal complains such as neck pain, cervicogenic headache, carpal tunnel syndrome, and impingement syndrome.

\section{Conclusion}

This study displayed that both RSP and FHRSP have no effect on hand grip strength in asymptomatic young adults. Moreover, the RSP and FHRSP were not associated with an inverse effect on the hand grip strength. Further research investigating the strength of hand grip in symptomatic patients with FHP and RSP may have significant implications in preventing the secondary distal affections.

\section{Abbreviations}

ANOVA: Analysis of variance; BMl: Body mass index; CVA: Craniovertebral angle; ES: Effect size; FHP: Forward head posture; FHRSP: Forward head and rounded shoulder posture; RSP: Rounded shoulder posture; SPSS: Statistical Package for Social Sciences

\section{Acknowledgements}

We would like to thank all participants for their patience and cooperation.

\section{Authors' contributions}

All authors approved the final manuscript file. DD contributed to the conception, design of the work, acquisition and analysis of the data, interpretation of the data, and drafting of the work and substantively revised it. AA contributed to the conception, design of the work, acquisition and analysis of the data, interpretation of the data, and drafting of the work and substantively revised it. Gl contributed to the conception, design of the work, acquisition, analysis, and drafting of the work and substantively revised it. EA contributed to the conception, design of the work, acquisition, analysis, and drafting of the work and substantively revised it. KS contributed to the conception, design of the work, acquisition, analysis, and drafting of the work and substantively revised it.

\section{Funding}

This paper was not funded.

\section{Availability of data and materials \\ $\mathrm{n} / \mathrm{a}$}

Ethics approval and consent to participate

The study was approved by the ethical committee of the Faculty of Physical Therapy, Cairo University (P.T.REC/012/001881). A written consent was obtained from the participants.

\section{Consent for publication}

This study was accepted for publication in BFPT on February 9, 2020.

\section{Competing interests}

There are no conflicts of interest that may have influenced this paper.

\section{Author details}

${ }^{1}$ Department of Basic Science, Faculty of Physical Therapy, Cairo University, Giza, Egypt. ${ }^{2}$ Department of Basic Science, Faculty of Physical Therapy, Badr University in Cairo, Badr City, Egypt. ${ }^{3}$ Department of Biomechanics, Faculty of 
Physical Therapy, Cairo University, 7 Ahmed Elziat Street, Ben Elsaryat, Eldokki, Giza 12611, Egypt. ${ }^{4}$ Department of Physical Therapy, Al-Mataria Teaching Hospital, El Matareya, Egypt.

Received: 1 May 2020 Accepted: 18 May 2020

Published online: 09 July 2020

\section{References}

1. Kratěnová J, Žejglicová K, Malý M, Filipová V. Prevalence and risk factors of poor posture in school children in the Czech Republic. J Sch Health. 2007; 77(3):131-7. https://doi.org/10.1111/j.1746-1561.2007.00182.x.

2. Greenfield B, Catlin PA, Coats PW, Green E, McDonald JJ, North C. Posture in patients with shoulder overuse injuries and healthy individuals. J Orthop Sports Phys Ther. 1995;21(5):287-95. https://doi.org/10.2519/jospt.1995.21.5.287.

3. Griegel-Morris P, Larson K, Mueller-Klaus K, Oatis CA. Incidence of common postural abnormalities in the cervical, shoulder, and thoracic regions and their association with pain in two age groups of healthy subjects. Phys Ther. 1992;72:425-31. https://doi.org/10.1093/ptj/72.6.425.

4. Cho C-Y. Survey of faulty postures and associated factors among Chinese adolescents. J Manip Physiol Ther. 2008;31:224-9.

5. Naz A, Bashir MS, Noor R. Prevalance of forward head posture among university students. Rawal Med J. 2018:43(2):260-2.

6. Hajibashi A, Amiri A, Sarrafzadeh J, Maroufi N, Jalaei S. Effect of kinesiotaping and stretching exercise on forward shoulder angle in females with rounded shoulder posture. JRSR. 2014;1(4):78-83.

7. Lee J-H. Effects of forward head posture on static and dynamic balance control. J Phys Ther Sci. 2016. https://doi.org/10.1589/jpts.28.274.

8. Amina D, Hawarib M, Hassanc HES, Elhafez HM. Effect of sex and neck positions on hand grip strength in healthy normal adults: a cross-sectional, observational study. Bull Fac Phys Ther. 2016;21(1):42-7. https://doi.org/10. 4103/1110-6611.188028.

9. Harrison DE, Cailliet R, Harrison DD, Troyanovich SJ, Harrison SO. A review of biomechanics of the central nervous system - Part II: spinal cord strains from postural loads. J Manip Physiol Ther. 1999. https://doi.org/10.1016/ S0161-4754(99)70065-5.

10. Kim E-K, Kim JS. Correlation between rounded shoulder posture, neck disability indices, and degree of forward head posture. J Phys Ther Sci. 2016. https://doi.org/10.1589/jpts.28.2929.

11. Viriyatharakij N, Chinkulprasert C, Rakthim N, Patumrat J, Ketruang B. Change of pectoralis minor length, and acromial distance, during scapular retraction at $60^{\circ}$ shoulder elevation. J Bodyw Mov Ther. 2017. https://doi.org/10.1016/j. jbmt.2016.04.015.

12. Kee IK, Byun JS, Jung JK, Choi JK. The presence of altered craniocervical posture and mobility in smartphone-addicted teenagers with temporomandibular disorders. J Phys Ther Sci. 2016;28(2):339-46. https:// doi.org/10.1589/jpts.28.339.

13. Kocur P, Tomczak M, Wiernicka M, Goliwąs M, Lewandowski J, Łochyński D. Relationship between age, BMI, head posture and superficial neck muscle stiffness and elasticity in adult women. Sci Rep. 2019. https://doi.org/10. 1038/s41598-019-44837-5.

14. Edmondston SJ, Wallumrød ME, MacLéid F, Kvamme LS, Joebges S, Brabham GC. Reliability of isometric muscle endurance tests in subjects with postural neck pain. J Manip Physiol Ther. 2008. https://doi.org/10.1016/j. jmpt.2008.04.010.

15. Kwon JW, Son SM, Lee NK. Changes in upper-extremity muscle activities due to head position in subjects with a forward head posture and rounded shoulders. J Phys Ther Sci. 2015. https://doi.org/10.1589/jpts.27.1739.

16. Yoosefinejad AK, Ghaffarinejad F, Hemati M, Jamshidi N. Comparison of grip and pinch strength in young women with and without hyperkyphosis: a cross-sectional study. J Back Musculoskelet Rehabil. 2019. https://doi.org/10. 3233/BMR-170932

17. Merolla G, De Santis E, Campi F, Paladini P, Porcellini G. Supraspinatus and infraspinatus weakness in overhead athletes with scapular dyskinesis: strength assessment before and after restoration of scapular musculature balance. Musculoskelet Surg. 2010. https://doi.org/10.1007/s12306-010-0082-7.

18. Borstad JD, Ludewig PM. The effect of long versus short pectoralis minor resting length on scapular kinematics in healthy individuals. J Orthop Sports Phys Ther. 2005. https://doi.org/10.2519/jospt.2005.35.4.227.

19. Fong PWK, Ng GYF. Effect of wrist positioning on the repeatability and strength of power grip. Am J Occup Ther. 2001. https://doi.org/10.5014/ajot. 55.2.212.
20. Mathiowetz V, Weber K, Volland G, Kashman N. Reliability and validity of grip and pinch strength evaluations. J Hand Surg [Am]. 1984. https://doi. org/10.1016/S0363-5023(84)80146-X.

21. Norman K, Stobäus N, Gonzalez MC, Schulzke JD, Pirlich M. Hand grip strength: outcome predictor and marker of nutritional status. Clin Nutr. 2011. https://doi.org/10.1016/j.clnu.2010.09.010.

22. Shin YJ, Kim WH, Kim SG. Correlations among visual analogue scale, neck disability index, shoulder joint range of motion, and muscle strength in young women with forward head posture. J Exerc Rehabil. 2017. https://doi. org/10.12965/jer.1734956.478.

23. Contractor ES, Shah SSS. To study correlation between neck pain and cranio-vertebral angle in young adults. Int Arch Integr Med. 2018;5(4):81-6.

24. Kang J-H, Park R-Y, Lee S-J, Kim J-Y, Yoon S-R, Jung K-I. The effect of the forward head posture on postural balance in long time computer based worker. Ann Rehabil Med. 2012:36:98-104. https://doi.org/10.5535/arm.2012.36.1.98.

25. Edmondston SJ, Sharp M, Symes A, Alhabib N, Allison GT. Changes in mechanical load and extensor muscle activity in the cervico-thoracic spine induced by sitting posture modification. Ergonomics. 2011. https://doi.org/ 10.1080/00140139.2010.544765.

26. Bokaee F, Rezasoltani A, Manshadi FD, Naimi SS, Baghban AA, Azimi H. Comparison of cervical muscle thickness between asymptomatic women with and without forward head posture. Brazilian J Phys Ther. 2017. https:// doi.org/10.1016/j.bjpt.2017.04.003.

27. Cheon SH, Park SH. Changes in neck and upper trunk muscle activities according to the angle of movement of the neck in subjects with forward head posture. J Phys Ther Sci. 2017. https://doi.org/10.1589/jpts.29.191.

28. Kim DH, Kim CJ, Son SM. Neck pain in adults with forward head posture: effects of craniovertebral angle and cervical range of motion. Osong Public Heal Res Perspect. 2018. https://doi.org/10.24171/j.phrp.2018.9.6.04.

29. Talavera-Carbajal MR, Estañol-Vidal B, López-Lomelí MM, et al. Monitoring dermatomal somatosensory evoked potentials at the ERB point, the cervical spinal cord and the cerebral cortex in the diagnosis of cervical radiculopathy. Rev Neurol. 2003;36(10):917-24.

30. Ruivo RM, Pezarat-Correia P, Carita Al. Intrarater and interrater reliability of photographic measurement of upper-body standing posture of adolescents. J Manip Physiol Ther. 2015. https://doi.org/10.1016/j.jmpt.2014.10.009.

31. Do Rosário JLP. Photographic analysis of human posture: a literature review. J Bodyw Mov Ther. 2014. https://doi.org/10.1016/j.jbmt.2013.05.008.

32. Wu W, Liang J, Du Y, et al. Reliability and reproducibility analysis of the Cobb angle and assessing sagittal plane by computer-assisted and manual measurement tools. BMC Musculoskelet Disord. 2014. https://doi.org/10. 1186/1471-2474-15-33.

33. Kim TW, An DI, Lee HY, Jeong HY, Kim DH, Sung YH. Effects of elastic band exercise on subjects with rounded shoulder posture and forward head posture. J Phys Ther Sci. 2016. https://doi.org/10.1589/jpts.28.1733.

34. Lam NW, Goh HT, Kamaruzzaman SB, Chin AV, Poi PJH, Tan MP. Normative data for hand grip strength and key pinch strength, stratified by age and gender for a multiethnic Asian population. Singap Med J. 2016. https://doi. org/10.11622/smedj.2015164.

35. Horsley I, Herrington L, Hoyle R, Prescott EBN. Do changes in hand grip strength correlate with shoulder rotator cuff function? Should Elb. 2016;8(2): 124-9.

36. Cohen J. Statistical power analysis of the behavioral sciences. 1988. https:// doi.org/10.1234/12345678,

37. Zafar $\mathrm{H}$, Alghadir AAS. Effects of head-neck positions on the hand grip strength in healthy young adults: a cross-sectional study. Biomed Res Int. 2018. https://doi.org/10.1155/2018/7384928.

38. Wong YCR, Cameron D, Bohannon RW. Elbow and hand muscle strength are not affected by head-neck position. Isokinet Exerc Sci. 1998.

39. Quinton Leroy S. Effects of forward head rounded shoulder posture on shoulder girdle flexibility, range of motion, and strength. 2006. doi:https:// doi.org/10.17615/5zyg-z666.

40. Talati D, Varadhrajulu G, Malwade M. The effect of forward head posture on spinal curvatures in healthy subjects. Asian Pacific J Heal Sci. 2018. https:// doi.org/10.21276/apjhs.2018.5.1.13.

41. Samaan MN, Elnegmy EH, Elnahhas AM, Hendawy A. Effect of prolonged smartphone use on cervical spine and hand grip strength in adolescence. Int J Multidiscip Res Dev. 2018:5(9):49-53.

42. DiVeta J, Walker ML, Skibinski B. Relationship between performance of selected scapular muscles and scapular abduction in standing subjects. Phys Ther. 1990. https://doi.org/10.1093/ptj/70.8.470. 
43. Smith J, Kotajarvi BR, Padgett DJ, Eischen JJ. Effect of scapular protraction and retraction on isometric shoulder elevation strength. Arch Phys Med Rehabil. 2002. https://doi.org/10.1053/apmr.2002.29666.

44. Incel NA, Ceceli E, Durukan PB, Rana Erdem H, Rezan YZ. Grip strength: effect of hand dominance. Singap Med J. 2002.

45. Han S, Nam K, Cho YRK. Normative data on hand grip strength. J Nov Physiother. 2011;1. https://doi.org/10.4172/2165-7025.1000102.

46. Ebram I. The effects of neck posture and head load on cervical spine and upper extremities. M Sc Thesis. 2014. https://doi.org/10.5455/jppa. 20141117043323.

47. Yang J, Lee J, Lee B, Jeon S, Han B, Han D. The effects of active scapular protraction on the muscle activation and function of the upper extremity. J Phys Ther Sci. 2014. https://doi.org/10.1589/jpts.26.599.

48. Mosa DMFN. Association between forward head posture and upper limb anthropometry in healthy adults. Med J Cairo Univ. 2017:85(7):2455-60.

49. Abbasi AH, Aslam M, Ashraf TMA. Evaluation of the forward head posture, its association with neck pain \& quality of life of female DPT students. J Riphah Coll Rehabil Sci. 2016;4(2):59-64.

50. Yong MS, Lee HY, Lee MY. Correlation between head posture and proprioceptive function in the cervical region. J Phys Ther Sci. 2016;16:38791. https://doi.org/10.1589/jpts.28.857.

51. Mateen S, Khan SA, Makhija M, Das S. Correlation of cranio-vertebral angle and cervical range of motion with pain, severity of symptoms and functional status in patients with carpal tunnel syndrome in Indian population. Indian J Physiother Occup Ther. 2012;6(4):101-5.

\section{Publisher's Note}

Springer Nature remains neutral with regard to jurisdictional claims in published maps and institutional affiliations.

\section{Submit your manuscript to a SpringerOpen ${ }^{\circ}$ journal and benefit from:}

- Convenient online submission

- Rigorous peer review

- Open access: articles freely available online

- High visibility within the field

- Retaining the copyright to your article

Submit your next manuscript at $\boldsymbol{\nabla}$ springeropen.com 